\title{
1 When anthraquinone dyes meet pillared montmorillonite: 2 stability or fading upon exposure to light? \\ 3
}

4 Pollyana Trigueiro ${ }^{1,2}$, Francisco Rodrigues Pereira ${ }^{1,3}$, David Guillemin ${ }^{1}$, Baptiste Rigaud ${ }^{4}$, Sebastien 5 Balme $^{5}$, Jean-Marc Janot ${ }^{5}$, Ieda M. G. dos Santos ${ }^{6}$, Maria G. Fonseca ${ }^{6}$, Philippe Walter ${ }^{1}$, Maguy 6 Jaber $^{1 *}$

7

8 9

${ }^{1}$ Universités, UPMC Paris06, UMR 8220, Laboratoire d'Archéologie Moléculaire et Structurale, 4 place Jussieu, F-75005 Paris, France

${ }^{2}$ Materials Engineering Department of Universidade Federal da Paraíba, João Pessoa, Paraíba, Brazil

${ }^{3}$ Chemistry Department of Universidade Estadual da Paraíba, Campina Grande, Paraíba, Brazil

${ }^{4}$ CNRS Institut des Matériaux de Paris Centre (FR2482), 4 place jussieu, 75005 Paris, France

${ }^{5}$ Institut Européen des Membranes, UMR 5635, Université de Montpellier, ENSCM, CNRS, Place Eugène Bataillon, F-34095 Montpellier cedex 5, France

${ }^{6}$ Chemistry Department of Universidade Federal da Paraíba, João Pessoa, Paraíba, Brazil

${ }^{7}$ Materials Engineering Department of Universidade Federal do Piaui, Teresina, Piaui, Brazil

Corresponding authors

*Maguy Jaber : maguy.jaber@upmc.fr 


\section{Abstract}

Hybrid pigments have attracted great interest due to their stability and physicochemical properties that can be used in paintings, artworks and in the field of cultural heritage. The study of new materials includes the search for new pigments by immobilization of the dyes in resistant substrates such clays minerals to get new color fonts and materials with high stability. Organic-inorganic based lake pigments, at different $\mathrm{pH}$, have been prepared. Ti- and Al-pillared montmorillonite were synthesized and loaded with carminic acid (CA) and alizarin (Aliz) organic dyes. The pillaring process was investigated by X-ray diffraction, textural analysis, transmission electronic microscopy and solid state nuclear magnetic resonance of ${ }^{27} \mathrm{Al}$. The interactions between the organic guest and the inorganic host were highlighted by infrared, ${ }^{13} \mathrm{C}$ and ${ }^{27} \mathrm{Al}$ solid state magnetic nuclear resonance and time resolved fluorescence spectroscopies. The spectra support complex formation between the chromophores and the inorganic matrix. The colours of the pigments prepared were $\mathrm{pH}$ dependent. Lake pigments based on Al-Pillared Mt were more stable under light than Ti-based hybrid, even in oil painting formulations.

Keywords: Hybrid pigment, Pillared clay, Carminic acid, Alizarin, NMR, Fluorescence, Photoaging. 


\subsection{Introduction}

Through centuries, paintings have represented the expression through art of some characteristics of human and social behaviour, also reflecting the impacts of environmental aspects. However, the poor stability of the colours used against acids, light or temperature has been a serious problem that has affected works of art and aspects of their cultural heritage as result of their public exposure. Thus, designs for stable pigments are desired in order to prepare/restore paintings and overcome the problem of degradation [1]. It has been expected that the surface where pigments are applied is a preponderant factor in determining the efficiency/stability of colours, and the perfection of paintings. Although there are many sources, there is a necessity to find combinations of raw materials for use as colouring agents/colourants in ink formulations. In fact, hybrid pigments have wide applications not only in works of art, but also in the fields of optics, food processing, cosmetics or plastics [24]. Hybrid based on organic dye-inorganic compounds are chemically obtained by a strong interaction between organic chromophores and inorganic matrices aiming to obtain stable pigments [8] or removing anionic dyes from wastewater [5]. In this context, a growing application of inorganic dyes-based hybrids are established [6-8].

Anthraquinones are classified as the natural organic dyes most resistant to light-induced deterioration used since prehistoric times [9]. These red colourants may be extracted from the roots of a diversity of plants from the Rubiaceae family (madder family). Alizarin and purpurin are the principal occurring dyes in Rubia tinctoria L. (maddergenus) [2,9]. Lakes are pigments formed from a dye-inorganic hybrid. Several other guest dyes have been reported in the literature to obtain lake pigments, such as carminic acid [1,8], fluorescein [8], betalain [10] and eosin [11]. 
Clays have attracted broad attention in the field of lake pigments because they are environment-friendly and low-cost materials and abundant in nature. Furthermore, some clay properties, such as high adsorption capacity and great potential for ion exchange, highlight their use as an inorganic support $[12,13]$. There are many confirmed examples of their use in clay-based lake pigments throughout history. A well-known example is "Maya Blue" which is a combination of indigo derived from the leaves of the local añil plant (Indigofera suffruticosa) with palygosrskite, a clay mineral of fibrous nature found in the Yucatán Peninsula [14]. The hybrid compound has conserved a strong blue colour in Mayan artworks up to this day. Recently, it has been some papers have reported clay-based lake pigments such as Maya Blue-like [15], acid-activated sepiolite/Rhodamine $\mathrm{B} @ \mathrm{SiO}_{2}$ fluorescent pigments [16], Halloysite/ $\mathrm{CoAl}_{2} \mathrm{O}_{4}$ hybrid pigments [7], Attapulgite/Fe (III) hybrid red pigments [3], $\mathrm{Fe}_{2} \mathrm{O}_{3}$ supported on sepiolite or halloysite [17], Carminic acid onto montmorillonite [1].

Among clay minerals, montmorillonite has attracted remarkable attention in the field of lakebased hybrids due to its peculiar features, such as swelling with a larger lamellar expansion capacity in aqueous solution. Moreover, its surface area negatively charged in an acid medium, enables it to interact with bulky molecules, such as cationic dyes $[1,18]$. Montmorillonite is a 2:1 type clay mineral, member of smectite group, with a hydrous layered aluminium silicate with a high cationic exchange capability (CEC) and active hydroxyl groups [19]. Its layers consist of two tetrahedral silica sheets sandwiching one octahedral aluminium sheet. The cationic layered clays can be transformed into highly porous structures by a process known as pillarization. Pillaring provides chemical and thermal stability to clays as well as increasing interlayer space and surface area [20,21]. The most common type of pillared clays is obtained by the incorporation of aluminium polyhydroxylations in the interlayer space of the clay, calcination is essential to ensure the formation of nanoscale 
alumina particles in the material [20,21]. Additionally, many other polycations formed upon hydrolysis of $\mathrm{Zr}^{4+}, \mathrm{Ti}^{4+}, \mathrm{Cr}^{3+}, \mathrm{Fe}^{3+}$ or $\mathrm{Ga}^{3+}$ were reported for pillaring clays [21,22]. In this perspective, the present investigation aimed to synthesize $\mathrm{Ti}$ - and Al-pillared montmorillonite and evaluate their influences on the photostability of new lake pigments and oil painting formulations. Alizarin (1,2-dihydroxyanthraquinone) and carminic acid (7-C- $\alpha-$ glucopyranosyl-3,5,6,8-tetrahydroxy-1-methyl-2-anthraquinone carboxylic acid) were used as dyeing agents.

\subsection{EXPERIMENTAL}

All chemicals applied in this work were purchased from Aldrich or Sigma-Aldrich with an analytical grade and used without any previous purification.

\subsection{Montmorillonite (Mt) synthesis}

The reagents were mixed in the following order: deionized water, hydrofluoric acid and the sources of interlamellar cation sodium acetate, magnesium acetate, alumina and silica. The hydrogel with the molar composition of $\mathrm{SiO}_{2} \cdot 0 \cdot 2 \mathrm{Al}_{2} \mathrm{O}_{3} \cdot 0.4 \mathrm{MgO} \cdot 0.05 \mathrm{Na}_{2} \mathrm{O} \cdot \mathrm{xH}_{2} \mathrm{O}$ was aged under stirring at room temperature for $2 \mathrm{~h}$ and then was autoclaved at $220^{\circ} \mathrm{C}$ for $72 \mathrm{~h}[19,23]$. The autoclaves were cooled to room temperature and the product were washed thoroughly with distilled water and centrifuged. Finally, the obtained Mt was dried at $50{ }^{\circ} \mathrm{C}$ for $72 \mathrm{~h}$.

\subsection{Pillaring process of Montmorillonite (PILC)}

The procedures for the pillaring process of Mt with aluminium polyhydroxycations and titanium ions followed the procedures adapted from Bergaoui et al [24] and Tomul et al [25], respectively. 
For aluminium, the pillaring solution was obtained by hydrolysis of aluminium chloride with a $\mathrm{NaOH}$ solution up to $\mathrm{OH}: \mathrm{Al}$ ratio of 2.2 and final concentration of $0.1 \mathrm{~mol} . \mathrm{L}^{-1}$. This mixture was left to stand for $24 \mathrm{~h}$ at room temperature under stirring. Meanwhile, $3.2 \mathrm{~g} . \mathrm{L}^{-1}$ of the aqueous clay suspension $\left(7.3 \mathrm{mmol} \mathrm{Al}^{3+}\right.$.g clay) was aged under stirring at room temperature for $3 \mathrm{~h}$. Then, aluminium solution was added dropwise to a clay suspension with flow of 1 $\mathrm{mL} . \mathrm{min}^{-1}$. The resulting solution was stirred $24 \mathrm{~h}$ at room temperature, washed and dried at 50 ${ }^{\circ} \mathrm{C}$ for $24 \mathrm{~h}$. The samples upon aluminium cations intercalation were denoted Al-Mt. The samples were calcined up to $500{ }^{\circ} \mathrm{C}$ for $2 \mathrm{~h}$. The pillared clay samples with aluminium cations were denoted PILC-Al.

For titanium, the pillaring solution was prepared by hydrolysis of titanium isopropoxide with $6 \mathrm{M} \mathrm{HCl}$ solution with $\mathrm{Ti}^{4+}: \mathrm{H}^{+}$molar ratio at $1: 4$. Titanium source solution was added dropwise with flow of $0.4 \mathrm{~mL} \cdot \mathrm{min}^{-1}$ and the result solution was left stirring at room temperature for $6 \mathrm{~h}$. Then, deionized water was added until reaching a concentration of $1 \mathrm{M}$ $\mathrm{H}^{+}$and $0.25 \mathrm{M} \mathrm{Ti}^{4+}$. The pillaring solution was introduced dropwise with a flow of $1 \mathrm{~mL} \cdot \mathrm{min}^{-1}$ to the Mt suspension until to reach $10 \mathrm{mmol} \mathrm{Ti}^{4+}$.g clay. The resulting suspension was stirred for $24 \mathrm{~h}$ at room temperature and then washed with deionized water until total chloride removal. The prepared solid was recovered by centrifugation and dried at $50{ }^{\circ} \mathrm{C}$ for $24 \mathrm{~h}$. Samples upon titanium cations intercalation were denoted Ti-Mt. The samples were calcined up to $400{ }^{\circ} \mathrm{C}$ for $2 \mathrm{~h}$. Pillared clay samples with titanium cations were denominated as PILCTi.

\subsection{Dyeing procedure}

Pillared montmorillonite was loaded with alizarin (Aliz) and carminic acid (CA) considering the different values of $\mathrm{pK}_{\mathrm{a}}$. It is known that carminic acid presents three different values of 
$\mathrm{pK}_{\mathrm{a}}(2.8,5.4$ and 8.1) [1,26], while alizarin has only two values (6.6 - 7.5 and $12.4-13.5)$ $[9,27]$.

For each sample, $300 \mathrm{mg}$ of pillared montmorillonite was added to $100 \mathrm{~mL}$ of carminic acid $\left(0.6\right.$ g. $\left.\mathrm{L}^{-1}\right)$ or alizarin $\left(0.8 \mathrm{~g} . \mathrm{L}^{-1}\right)$ solution and was left under stirring for $4 \mathrm{~h}$. The samples were then centrifugated, washed with deionized water and dried at $50{ }^{\circ} \mathrm{C}$ for $24 \mathrm{~h}$.

\subsection{Oil painting formulation}

All the formulations were obtained by incorporating $35 \mathrm{mg}$ of pigment in $400 \mu \mathrm{L}$ of linseed oil. The mixture was then grinded and an homogeneous paste is obtained. Films were then prepared on slice glasses using specific applicator. Linseed oil is one of the earliest and the most commonly vehicle applied to ink formulations that remains been used nowadays.

\subsection{CHARACTERIZATIONS}

\subsection{X-ray diffraction $(X R D)$}

Powder X-ray diffractograms were recorded using D8 Advance Bruker-AXS Powder X-ray diffractometer with $\mathrm{CuK}_{\alpha}$ radiation $(\lambda=1.5405 \AA)$. XRD patterns were performed between 5$70^{\circ}(2 \theta)$ with scan rate of 0.5 deg. $\min ^{-1}$. The active area of the detector was limited as much as possible in order to reduce the background scattering at low angle between $2-10^{\circ}(2 \theta)$.

\subsection{Textural investigation}

Nitrogen adsorption-desorption isotherms were measured at liquid nitrogen temperature on a Micromeritics ASAP 2020 apparatus. The specific surface area $\left(\mathrm{S}_{\mathrm{BET}}\right)$ was evaluated using the Brunauer-Emmett-Teller (BET) method. The pore size distribution was determined from the desorption part of the isotherm using the Barret-Joyner-Halender (BJH) method [28].

\subsection{Transmission electron microscopy (TEM)}


TEM study of the samples was performed on a JEOL 2010 microscope, $200 \mathrm{kV} \mathrm{LaB} 6$ coupled Orius camera, from Gatan Company. Samples in the form of bulk powders were suspended in ethanol and then deposited on 400 mesh copper grids covered with an ultrathin carbon membrane of $2-3 \mathrm{~nm}$ thickness.

\subsection{ATR-FTIR}

Infrared analyzes was performed on Agilent Cary 630 FTIR spectrometer using Agilent diamond Attenuated Total Reflectance (ATR) technique mode, being spectral resolution $>2$ $\mathrm{cm}^{-1}$ and 32 scans. Spectra were acquired by Microlab FTIR Software (Agilent Technologies). Spectra were acquired between 4000 and $650 \mathrm{~cm}^{-1}$.

\subsection{Thermal Analysis (TG/DTG)}

Thermogravimetric analyses were carried out using a TA Instrument SDT Q600 analyzer. The heating rate was of $5{ }^{\circ} \mathrm{C}$.min from $25{ }^{\circ} \mathrm{C}$ to $800{ }^{\circ} \mathrm{C}$, under dry air flow of $10 \mathrm{~mL}$.min, and using alumina pan.

\subsection{Solid state nuclear magnetic resonance $\left({ }^{13} \mathrm{C} C P-M A S\right.$ and $\left.{ }^{27} A l M A S-N M R\right)$}

${ }^{13} \mathrm{C}$ and ${ }^{27} \mathrm{Al}$ MAS NMR spectra were obtained on a Bruker Avance III spectrometer equipped with a $4 \mathrm{~mm} \mathrm{H-X}$ MAS probe, operating at frequency of $500.17 \mathrm{MHz}\left({ }^{1} \mathrm{H}\right), 125.77 \mathrm{MHz}\left({ }^{13} \mathrm{C}\right)$ and 130.33 $\mathrm{MHZ}\left({ }^{27} \mathrm{Al}\right)$. Chemical shifts were calibrated using the carboxyl signal of adamantane (38.52 ppm) for ${ }^{13} \mathrm{C}$ and $\mathrm{AlNO}_{3}\left(\mathrm{O}\right.$ ppm) for ${ }^{27} \mathrm{Al}$ as external standard.

The ${ }^{13} \mathrm{C}$ Cross-Polarization spectra were acquired with a MAS rate of $14 \mathrm{kHz}$, a ramp-CP contact time of $1 \mathrm{~ms}$ and a $1 \mathrm{~s}$ recycle delay and with a ${ }^{1} \mathrm{H}$ decoupling spinal. Over an acquisition time of $40 \mathrm{~ms}$, the number of scans to obtain the spectra depends on the $\mathrm{S} / \mathrm{N}$ obtained for each sample. Spectra were processed with a zero-filling factor of 2 and with an 
exponential decay corresponding to a $25 \mathrm{~Hz}$ line broadening in the transformed spectra. Only spectra with the same line broadening are directly compared.

The ${ }^{27} \mathrm{Al}$ experiment using $30^{\circ}$ pulse is recorded in the same condition of spinning rate, 100 $\mathrm{kHz}$ spectral width and with 500 ms recycle delay.

\subsection{Fluorescence Characterisation}

Time-resolved fluorescence spectroscopy was obtained by the time-correlated single-photon counting technique on lab-made device previously described [23,29]. For the analysis the fluorescence decay law at the magic angle $I_{M}(t)$ were analyzed as a sum of exponentials:

$$
\mathrm{I}_{\mathrm{M}}(\mathrm{t})=\frac{1}{3} \sum_{\mathrm{i}=1}^{\mathrm{n}} \alpha_{\mathrm{i}} \mathrm{e}^{-\mathrm{t} / \tau_{\mathrm{i}}}
$$

Where, $\tau_{i}$ is the fluorescence lifetime and $\alpha_{i}$ is the pre-exponential factor related to the contribution of each lifetime of the component $i$.

Fluorescence lifetimes were calculated from data collected at magic angle by iterative adjustment after convolution of a pump profile (scattered light) with a sum of exponentials as described previously. The criteria to evaluate the quality of fit are $\chi^{2}$ the and the residue function. The fluorescent decay was recorded at $\lambda_{\mathrm{em}}=600 \mathrm{~nm}$ under excitation $\lambda_{\mathrm{ex}}=540 \mathrm{~nm}$ or $\lambda_{\mathrm{em}}=550 \mathrm{~nm}$ for carminic acid and alizarin, respectively.

\subsection{Light-Induced Aging}

Aging effects were simulated by exposure of solid pigments and oil paint formulations to white light irradiation for 340 hours, using a LED lamp set to provide $50 \mathrm{Klx}$ of illumination intensity.

Spectrophotocolorimetry was performed using an Ocean Optics Halogen and Deuterium Light Source HL-2000-FHSA device as incident light beam and ocean optics USB4000 detector for 
acquisition. Ocean Optics QP400-1-UV-VIS fiberglass was used to link these devices. For each acquisition, an average of 100 scans were useful to obtain the optimum signal. The reflectance wavelength range was set from 400 to $950 \mathrm{~nm}$ and measurements are done on pressed pellets samples as function of $L^{*}, a^{*}$ and $b^{*}$ coordinates. The differences of colours between unexposed and exposed samples were calculated by $\sqrt{\left(\left(\Delta L^{*}\right)^{2}+\left(\Delta a^{*}\right)^{2}+\right.}$ $\left.\left(\Delta b^{*}\right)^{2}\right)$ equation, according to the "Commission Internationale of l'Eclairage" (CIE).

\subsection{RESULTS AND DISCUSSIONS}

\subsection{Structural and textural properties}

X-ray diffraction patterns of the raw Mt and pillared-Mt samples are depicted in Figure 1a-b. Characteristic peaks of the pristine clay were observed as reported previously [30]. The $d_{001}$ of the later is about $1.3 \mathrm{~nm}$ typical of one hydrated layer for Na-Mt. For PILC-A, $d$ value increases from $1.3 \mathrm{~nm}$ to $1.64 \mathrm{~nm}$ suggesting an intercalation of the aluminium cations into the interlayer space of Mt. Upon calcination, the $d_{001}$ value reached $1.75 \mathrm{~nm}$ due to the formation of oxide pillars as already reported [31,32].

In the case of titanium cations, the $d_{001}$ value varies from $1.3 \mathrm{~nm}$ to $1.45 \mathrm{~nm}$ (Figure $1 \mathrm{~b}$, insert) due to the increase of the interlayer space upon intercalation of titanium cations in Mt. After calcination, the (001) reflexion can not be observed anymore suggesting an heterogeneous stacking of the layer in the titanium pillared Mt samples $[25,33]$ or an exfoliation. A peak at $2 \theta=25.36$ characteristic of anatase $\left(\mathrm{TiO}_{2}\right)$ was observed as reported previously in Ti-pillared clay minerals [34-36].

After loading with dyes, no significant changes in the $\mathrm{d}_{001}$ values were found in the composite materials based on pillared-Mt and dyes. 
It is known that modification of clays by pillarization with metal oxides also causes the

227 increase of the specific area and promotes a permanent mesoporosity [37-39].
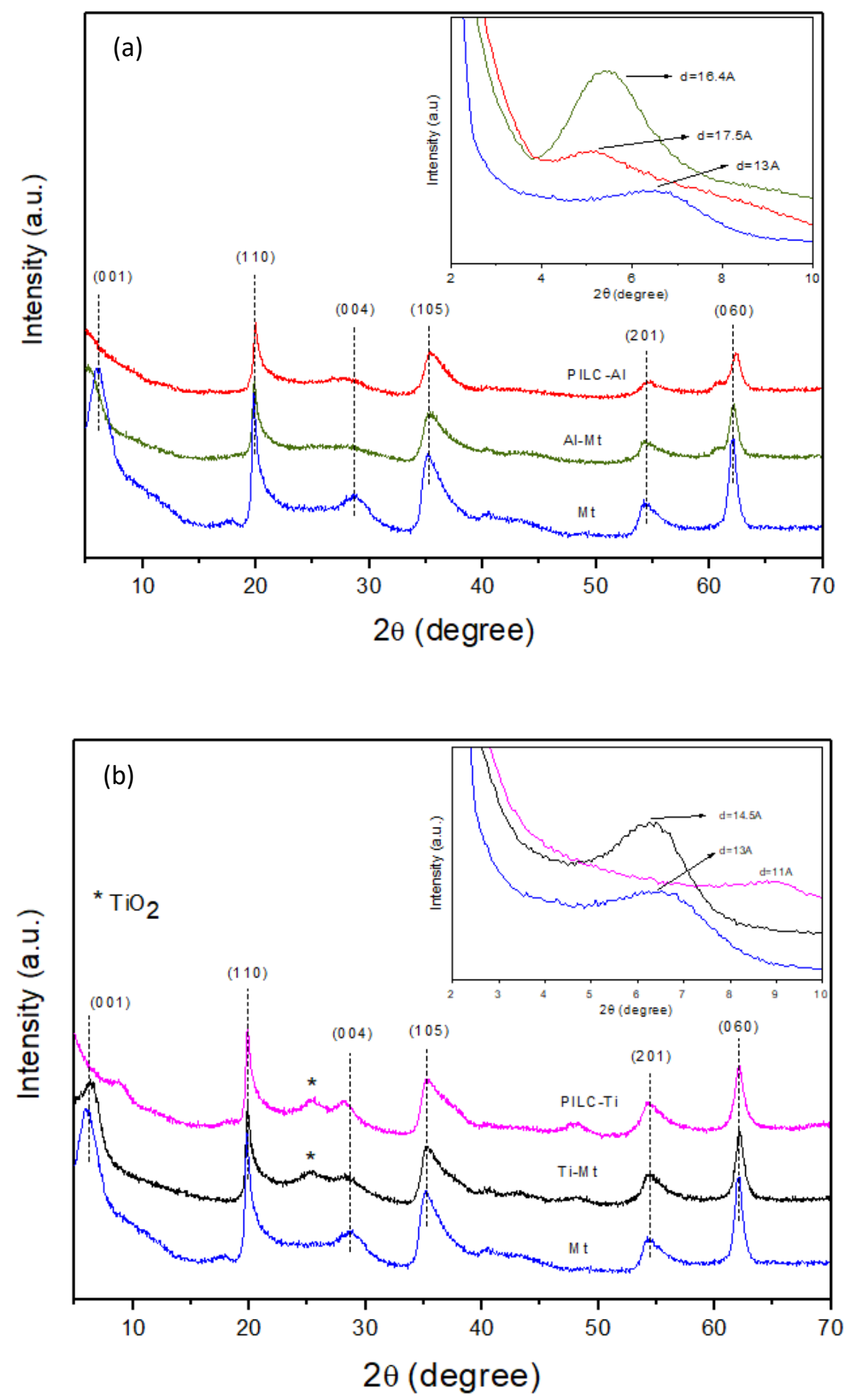

Figure 1. XRD patterns of pillared-Mt with (a) aluminium and (b) titanium cations, showing in insert the shift in the $d_{001}$ peak upon metallic cations intercalation and upon calcination of the samples. 
233 The $\mathrm{N}_{2}$-adsorption/desorption isotherms and pore size distribution of the pillared clays are 234 presented in Figure $2 \mathrm{a}$ and $2 \mathrm{~b}$. The adsorption isotherms of the pillared samples fit the Type 235 IV, for low relative pressures, the curve is characterized by a saturation step and presence of a 236 hysteresis loop of type $\mathrm{H}_{4}$ [34]. This kind of adsorption isotherm is typical of mesoporous 237 materials [35]. The multipoint BET surface area $\left(\mathrm{S}_{\mathrm{BET}}\right)$ values were determined from isotherm 238 data in the $\mathrm{P} / \mathrm{P}_{0}$ 0.09-0.5 range. The raw clay reached a surface area of $106 \mathrm{~m}^{2} \cdot \mathrm{g}^{-1}$, while 239 PILC-Al and PILC-Ti exhibited values of $186 \mathrm{~m}^{2} \cdot \mathrm{g}^{-1}$ and $204 \mathrm{~m}^{2} \cdot \mathrm{g}^{-1}$, respectively. A narrow 240 size distribution of the mesopores obtained by BJH method showed a diameter range between 241 3-5 nm and 3-6 nm for the PILC-Al and PILC-Ti samples, respectively (Figure 2b). These 242 results suggested that the pillaring process succeed in the PILC-Al and PILC-Ti samples. 

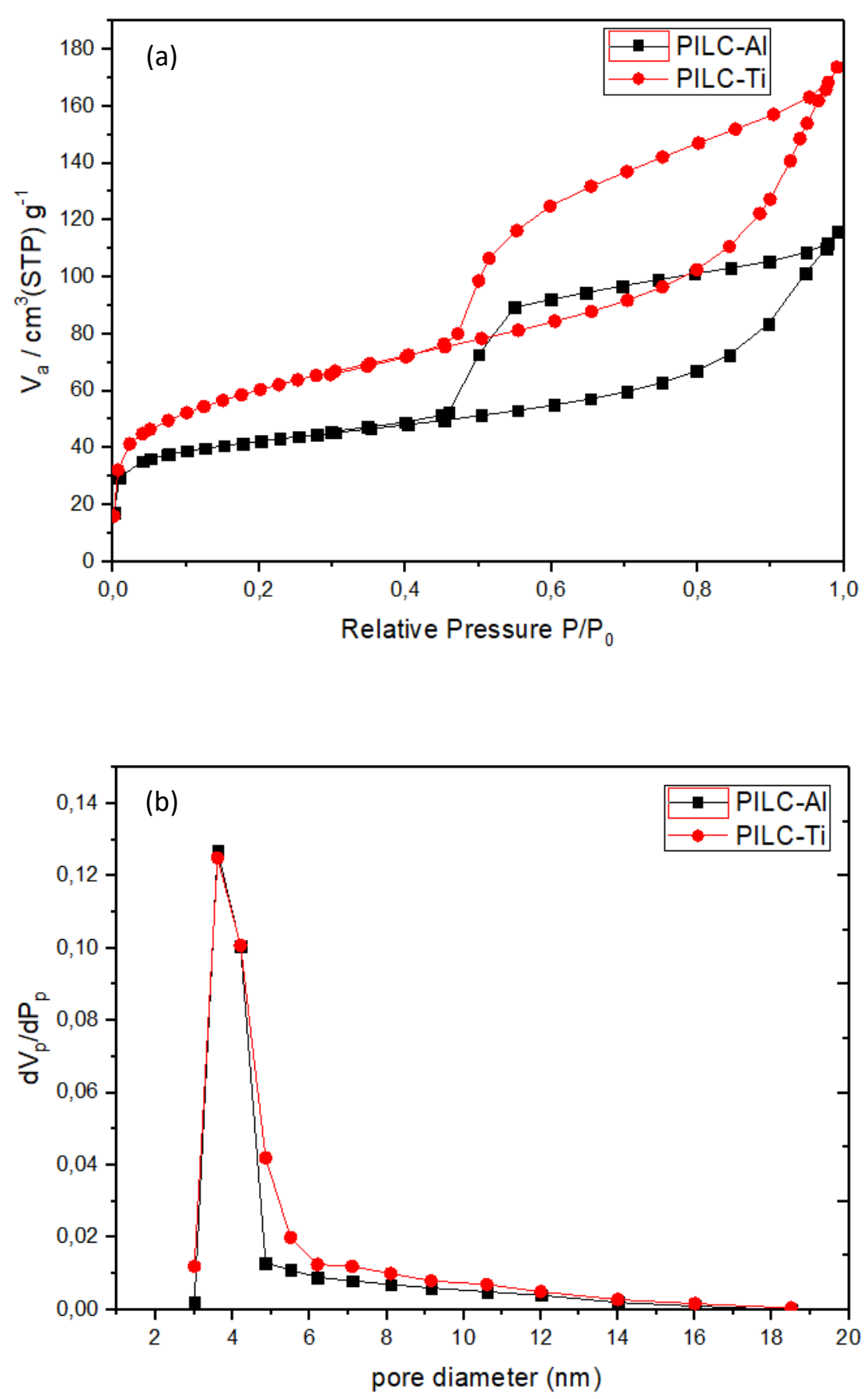

245 Figure 2. (a) $\mathrm{N}_{2}$ isotherms of adsorption/desorption at $77 \mathrm{~K}$ and (b) pore diameter $\left(\mathrm{d}_{\mathrm{p}}\right)$ distribution for 246 PILC-Al and PILC-Ti samples. 
TEM experiments were performed to have a better view of the intercalation of the metal cations in the interlayer of montmorillonite. TEM images of Mt shows layered structures with alternate dark and bright fringes with a calculated interlayer distance of $1.26 \mathrm{~nm}$ for the raw sample. It was noticed that the distance increased to $1.75 \mathrm{~nm}$ and about $1.4-1.8 \mathrm{~nm}$ for PILCAl and PILC-Ti samples, respectively (Figure 3a-b). The results suggested that the pillaring process occurs and that the lamellar structure of Mt was maintained for both samples, in agreement with the XRD results.

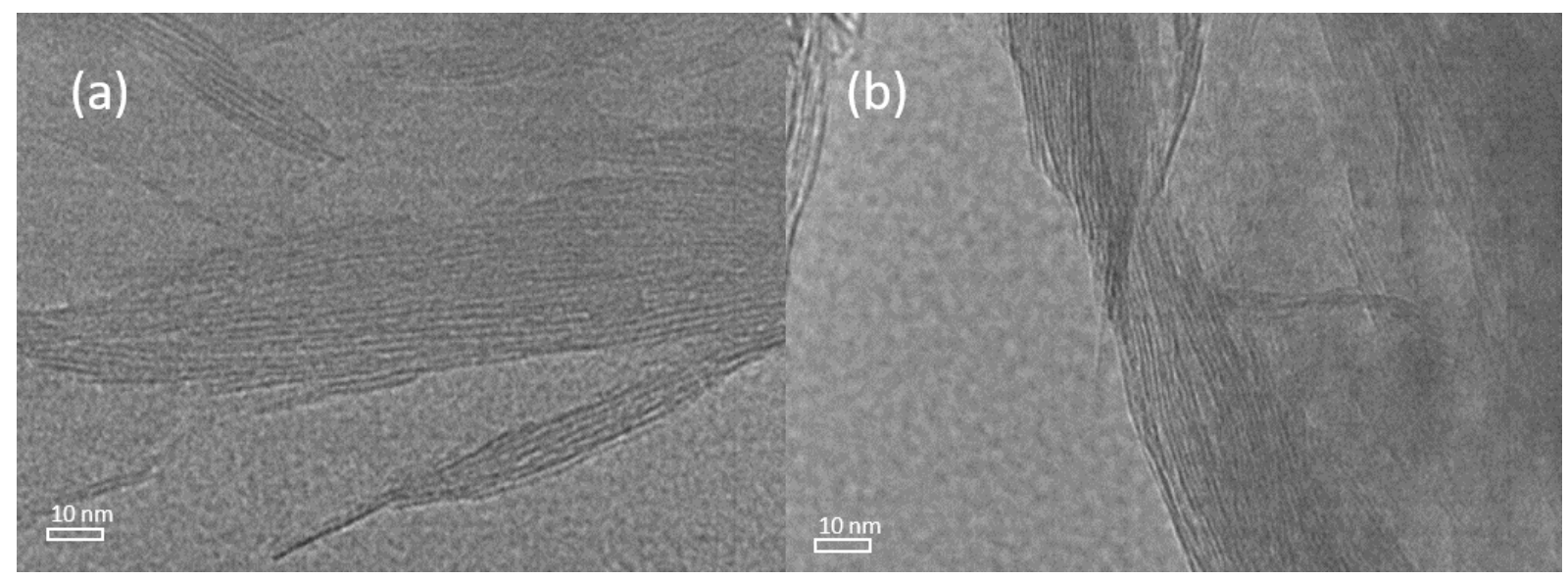

Figure 3. TEM images of (a) PILC-Al and (b) PILC-Ti samples.

\subsection{ATR-Infrared}

ATR-IR spectra of the pillared clay samples before and after adsorption of carminic acid and alizarin dyes are shown in Figure 4a-b. It can be noticed several characteristic bands of the dyes related to anthraquinone groups. Spectrum of bulk CA (Figure 4a) showed bands at 1611 $\mathrm{cm}^{-1}, 1563 \mathrm{~cm}^{-1}$ and $1428 \mathrm{~cm}^{-1}$ corresponding to the stretching vibration of $v(C=O)$ quinone group, stretching vibration of $v(C=C)$ aromatic and bending vibration of $\delta(\mathrm{OH})$ group, respectively. Bulk Aliz (Figure 4b) spectrum shows bands at $1663 \mathrm{~cm}^{-1}, 1587 \mathrm{~cm}^{-1}$ and 1453 $\mathrm{cm}^{-1}$ corresponding to the stretching vibration of $\mathrm{v}(\mathrm{C}=\mathrm{O})$ quinone group, stretching vibration of $v(C=C)$ aromatic and bending vibration to $\delta(\mathrm{OH})$ group, respectively [8]. Spectra of hybrid pigments with CA present shifts for some bands, in Figure 4a, the band of $\mathrm{C}=\mathrm{C}$ structure 
268 shifts from 1563 to $1558 \mathrm{~cm}^{-1}$ in PILC-Al-CA-pH2.5 and to $1566 \mathrm{~cm}^{-1}$ in PILC-Ti-CA-pH2.5.

269 For the $\mathrm{C}=\mathrm{O}$ function the band disappeared upon adsorption, the band corresponding to $\mathrm{OH}$ 270 group is shifted from 1428 to $1440 \mathrm{~cm}^{-1}$ in PILC-Al-CA-pH2.5 and to $1442 \mathrm{~cm}^{-1}$ in PILC-Ti-

271 CA-pH2.5. In the case of hybrid pigments with Aliz, in Figure 4b, the band assigned to the 272 stretching vibration $\mathrm{C}=\mathrm{C}$ aromatic shifts from 1587 to $1590 \mathrm{~cm}^{-1}$ for PILC-Al-Aliz-pH8.4 and 273 to $1591 \mathrm{~cm}^{-1}$ in PILC-Ti-Aliz-pH8.4, the band corresponding to $\mathrm{C}=\mathrm{O}$ group presented similar 274 behaviour as CA, the band is not observed upon adsorption on clay. Finally, the band 275 corresponding to bending vibration $\mathrm{OH}$ shift from 1453 to $1468 \mathrm{~cm}^{-1}$ for PILC-Al-Aliz-pH8.4 276 and to $1466 \mathrm{~cm}^{-1}$ in PILC-Ti-Aliz-pH8.4. These results indicate that the coordinated bonds 277 between anthraquinone groups and modified clay minerals can occur by chelation of $\mathrm{Al}^{3+}$ and $278 \mathrm{Ti}^{4+}$ cations of the pillars with the quinone and catechol functions of the dyes as well as by 279 adsorption of the dyes onto external and internal surface of clay mineral. 

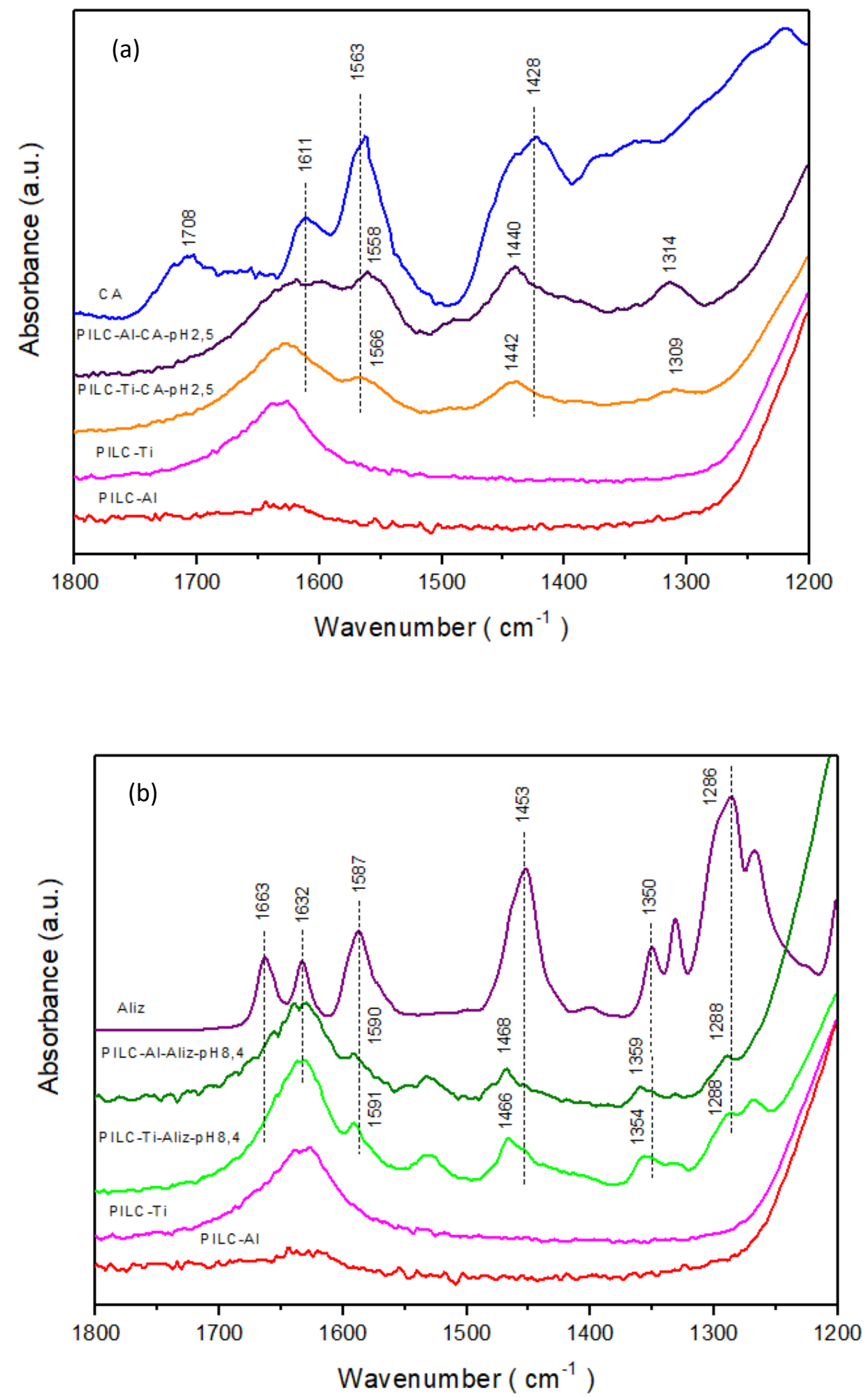

281 Figure 4. ATR-IR spectra of pillared clays and dyed clays with (a) carminic acid and (b) alizarin. 
DTG curves for all samples are depicted in Figure 5. The characteristic stages of the mass loss of water, organic matter and dehydroxylation, before and after adsorption of CA and Aliz dyes are shown.

Two regions of mass loss have been noticed for the raw Mt and pillared clays samples. The first one, with an endothermal event, with weight loss about $4.3-5 \%$ at $\mathrm{T}_{\max }=45{ }^{\circ} \mathrm{C}$ is attributed to the departure of physisorbed water. The second at $\mathrm{T}_{\max }=630{ }^{\circ} \mathrm{C}$, with an endothermal event, is attributed to structural dehydroxylation of the clay matrix with mass loss about $2.0 \%$ for both samples [40].

After the dyeing process, the first peak corresponds to the dehydration with an amount between $6.5-8 \%$. The second peak between 350 and $560{ }^{\circ} \mathrm{C}$ for all samples corresponds to the oxidation of the organic matter. PILC-Ti dyed clays has $3.2 \%$ of weight loss corresponding to alizarin dye and $3.5 \%$ of carminic acid dye decomposition. PILC-Al dyed clays presents about $7.8 \%$ of alizarin dye and $6.5 \%$ of carminic acid dye decomposition. All the samples still show the peak related to dehydroxylation with a weight loss between 1.5-2.2 \%

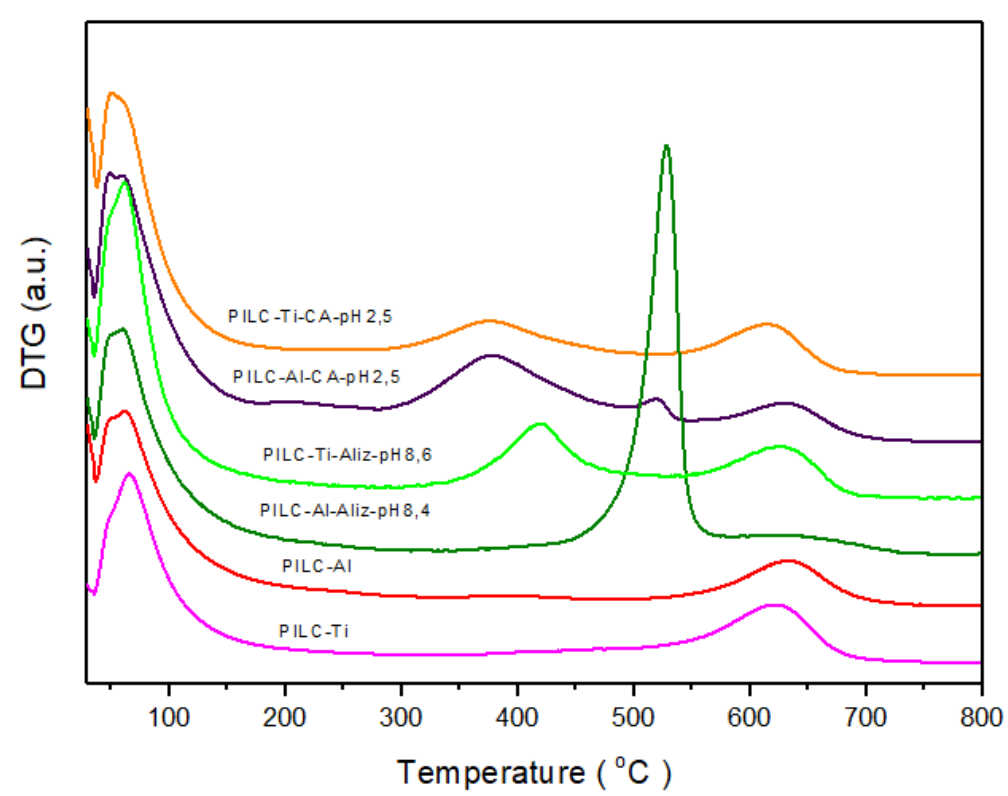


Figure 5. DTG curves for PILC-T, PILC-A, PILC-A-Aliz-pH8.6, PILC-T-Aliz-pH8.4, PILC-A-CA-pH2.5 and PILC-T-CA-pH2.5 dyed samples.

301

4.5 Solid state nuclear magnetic resonance of ${ }^{13} \mathrm{C}$ and ${ }^{27} \mathrm{Al}$

${ }^{27} \mathrm{Al}$ MAS NMR spectra of PILC-Al before and after adsorption of CA and Aliz dyes are depicted in Figure 6. PILC-Al sample presented three characteristic chemical shifts at 3.4 ppm, $59.6 \mathrm{ppm}$ and $28.6 \mathrm{ppm}$ related to hexa-coordinated-Al (Al VI), tetra-coordinated-Al (Al IV) and penta-coordinated-Al ( $\mathrm{Al} \mathrm{V})$, respectively. The intense peak of $\mathrm{Al}$ (VI) corresponds to the $\mathrm{Al}$ in the pillars and the $\mathrm{Al}(\mathrm{IV})$ signals are resulted of a overlap of the central $\mathrm{Al}$ in $\mathrm{Al}_{13}$ (Keggin structure with a tetrahedral $\mathrm{Al}$ atom in the centre of the cluster coordinated to 4 oxygen atoms) and small amount of $\mathrm{Al}$ in the tetrahedral sheets [24]. It has been noticed a shift from 3.4 to 3.3 ppm and from 3.4 to 3.2 ppm for PILC-Al-Aliz-pH8.4 and PILC-Al-CApH2.5 dyed samples, respectively. This may suggest the interactions between Aliz or CA and $\mathrm{Si}-\mathrm{OH}-\mathrm{Al}-\mathrm{OH}$ in the Mt edges well as with pillars formation.

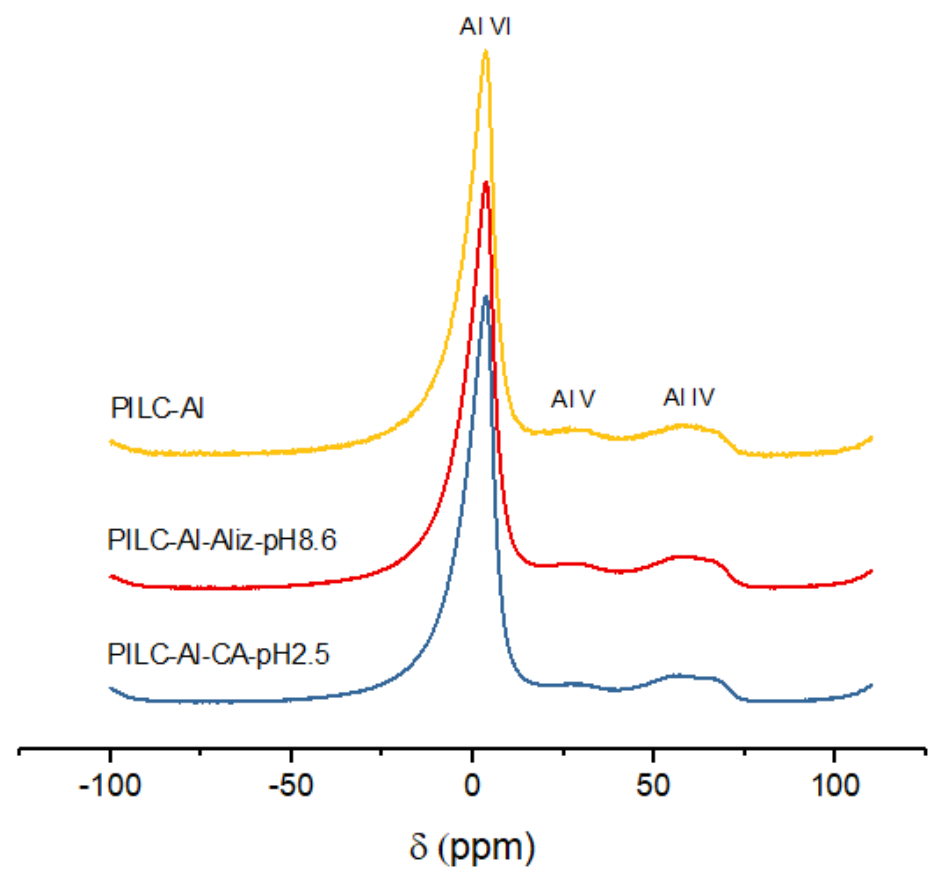


${ }^{13} \mathrm{C}$ MAS NMR spectra of the Al and Ti-pillared clay samples after adsorption with CA are

317 presented in the Figure 7a. Although the spectra of the CA onto pillared clays composites

318 exhibited almost the same signals than the raw dye, it was observed some changes in the

319 chemical shifts. In bulk CA, the signal at $20.9 \mathrm{ppm}$ is related to methyl group of C8 and the

320 region between $60-80 \mathrm{ppm}$ is attributed to the sugar part of the dye molecule. The signals at

$321 \quad 171.3 \mathrm{ppm}$ and $185 \mathrm{ppm}$ are assigned to the carboxylate moieties and to the ketones functions,

322 respectively [1]. Some other shifts have been observed, upon complexation, such as from

$323 \quad 147.5 \mathrm{ppm}$ to $149.2 \mathrm{ppm}$ and $148.3 \mathrm{ppm}$, attributed to $\mathrm{C} 4$ signal for PILC-Al-CA-pH2.5

324 sample and PILC-Ti-CA-pH2.5, respectively. The C5 signal is shifted from 112.5 to 115.2

$325 \mathrm{ppm}$ and $114.1 \mathrm{ppm}$ to PILC-Al-CA-pH2.5 and PILC-Ti-CA-pH2.5, respectively. In the

326 region of the $\mathrm{C} 9,10$ the signal is not well defined for PILC-Al-CA-pH2.5 and is shifted from

327185 to $186.7 \mathrm{ppm}$ for PILC-Ti-CA-pH2.5. This may suggest the chelation between the

328 metallic cations and anthraquinone groups in the dyes. Indeed, dye may also be adsorbed in

329 clay surface. The chromophore groups in anthraquinone dyes can also behave as binding

330 functions between the dye molecule and the mineral support through an intermediate metal

331 atom [9]. 

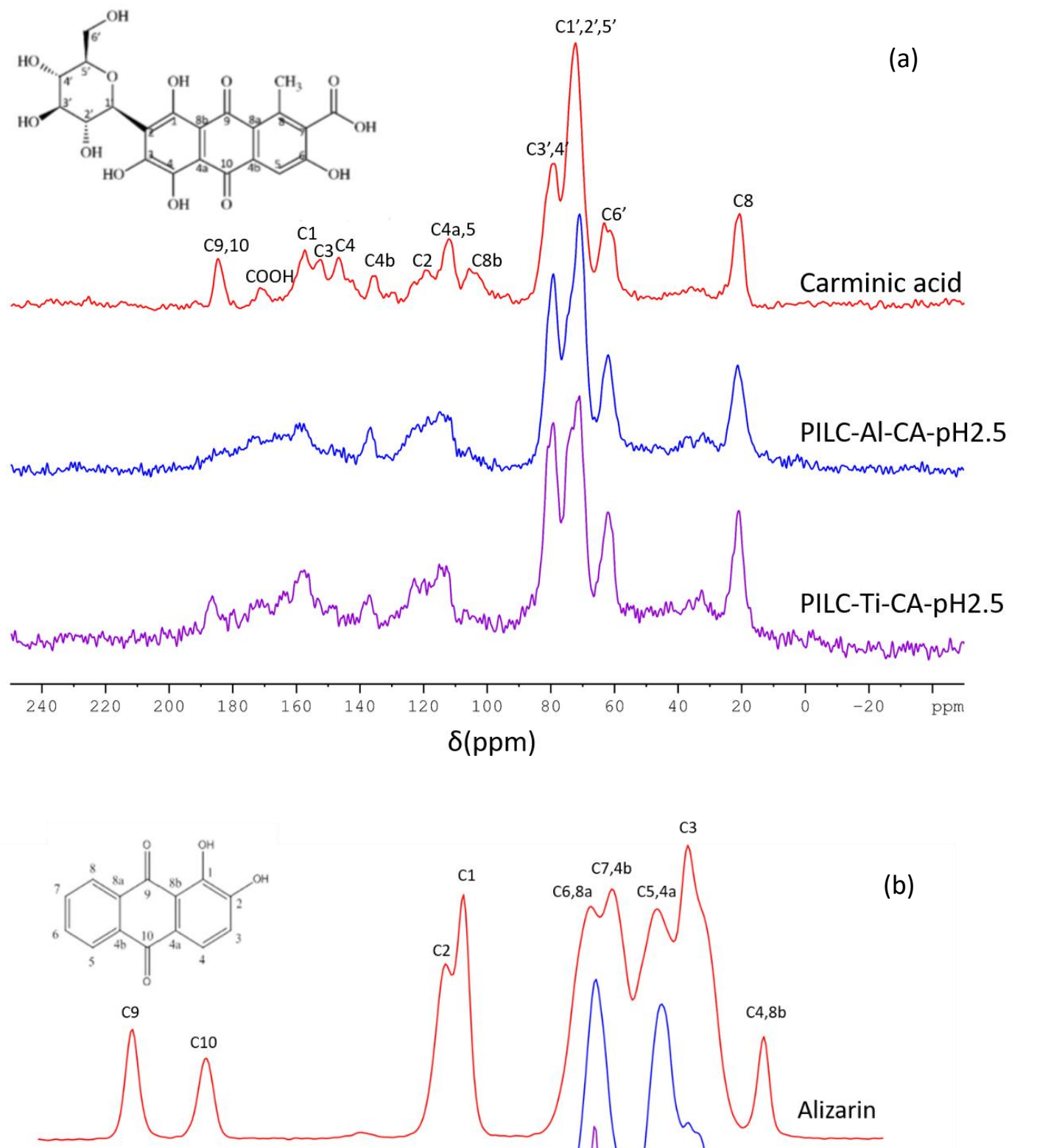

(b)

Alizarin
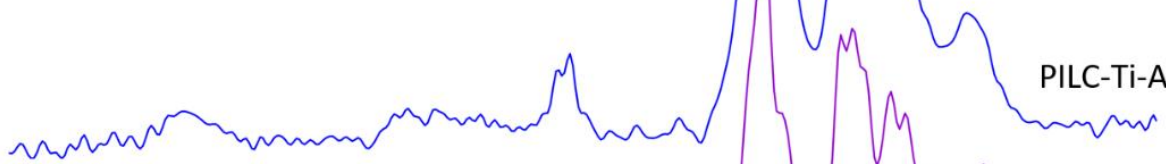

PILC-Al-Aliz-pH8.6

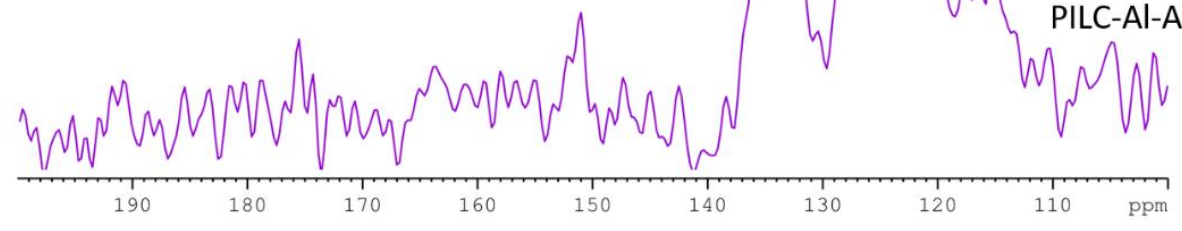

$\delta(\mathrm{ppm})$

Figure 7. ${ }^{13} \mathrm{C}$ MAS NMR spectra of Al and Ti-pillared clays and dyed clays with (a) carminic acid and (b) alizarin. 
${ }^{13} \mathrm{C}$ MAS NMR spectra of the $\mathrm{Al}$ and Ti-pillared clay samples after adsorption with Aliz are presented in the Figure 7b. Alizarin has distinct region for the resonances of the anthraquinone partial structure and hydroxy groups. The peaks corresponding to $\mathrm{C} 1$ and $\mathrm{C} 2$, that are assigned to hydroxyl groups, are shifted from 150 and $151.8 \mathrm{ppm}$ to one signal at 151.2 ppm and 151.4 ppm to PILC-Ti-Aliz-pH8.4 and PILC-Al-Aliz-pH8.6, respectively. It was notice that the signals assigned to $\mathrm{C} 9$ and $\mathrm{C} 10$ corresponding to ketone functions shifts to shoulder not well defined at approximately $184 \mathrm{ppm}$ in both pillared clays. The results suggested that the ketone and hydroxyl groups of the dyes can be main attachment site with the modified inorganic matrix [41,42].

\subsection{Fluorescence analysis}

The time resolved fluorescence characterisation of carminic acid and alizarin free in solution and loaded on pillared clay were performed under wavelength excitation $540 \mathrm{~nm}$ and $550 \mathrm{~nm}$ respectively (Figure 8). Free in solution, the average fluorescence lifetimes are $0.151 \mathrm{~ns}$ and $0.596 \mathrm{~ns}$ for carminic acid and alizarin, respectively. They significantly increase after adsorption on pillared clay (tables I and II). This result confirms a stabilisation of both dyes due to their interactions with the clay as shown by NMR.

The fluorescence decay of the alizarin free in solution and adsorbed on all materials requires three components to be fitted. For the PILC-Ti, similar results were obtained at $\mathrm{pH} 7.1$ and 3.4 suggesting similar interactions between the dye and the pillared clay. On the contrary, for PILC-Al the $\mathrm{pH}$ influences the fluorescence lifetime and thus the interaction are not the same, due different degrees of protonation of the molecule in these $\mathrm{pH}$. The different lifetimes at $\mathrm{pH}$ around 7-8 for PILC-Ti and PILC-Al dyed with Alizarin confirms that the cation (Al or Ti) is involved in the interaction material/dyes. 
360 For the carminic acid, the fluorescence results are quite different. In solution, the fluorescence 361 decay is composed by three lifetimes ( $0.496 \mathrm{~ns}, 0.099 \mathrm{~ns}$, and $0.048 \mathrm{~ns})$. After loading on 362 pillared clays, it requires four components among them one component longer than $1.5 \mathrm{~ns}$ 363 appears. It also depends on the metal cations used for the pillaring process confirming its role 364 in the material/dye interaction. Moreover, the degree of protonation influences the 365 fluorescence emission properties. Indeed, for PILC-Ti-pH5 the average lifetime is $0.945 \mathrm{~ns}$ and the longer component represents $25.6 \%$ of the global decay while for PILC-Ti-pH2.5 the 367 average lifetime is shorter (0.469 ns) and the longer component $1.723 \mathrm{~ns}$ represents less than $10 \%$. At $\mathrm{pH} 5$, the carboxyl group is deprotonated and thus can be coordinated with 369 aluminium by electrostatic interactions. On the contrary at $\mathrm{pH} 2.5$ the carminic acid is totally 370 protonated and thus the complexation with aluminium likely involved the anthraquinone and/or clay surface as suggested by NMR study.

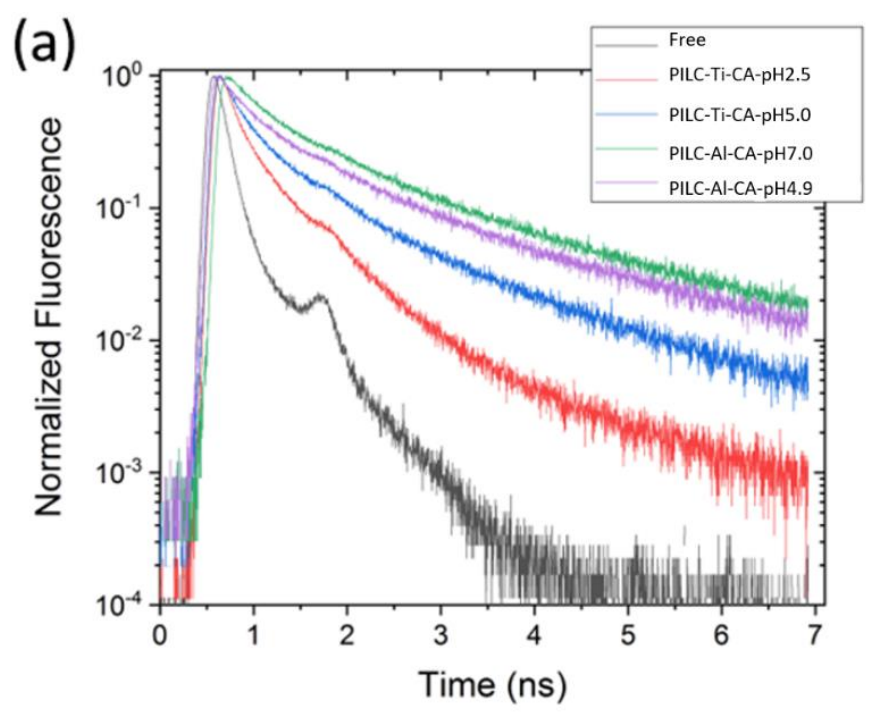




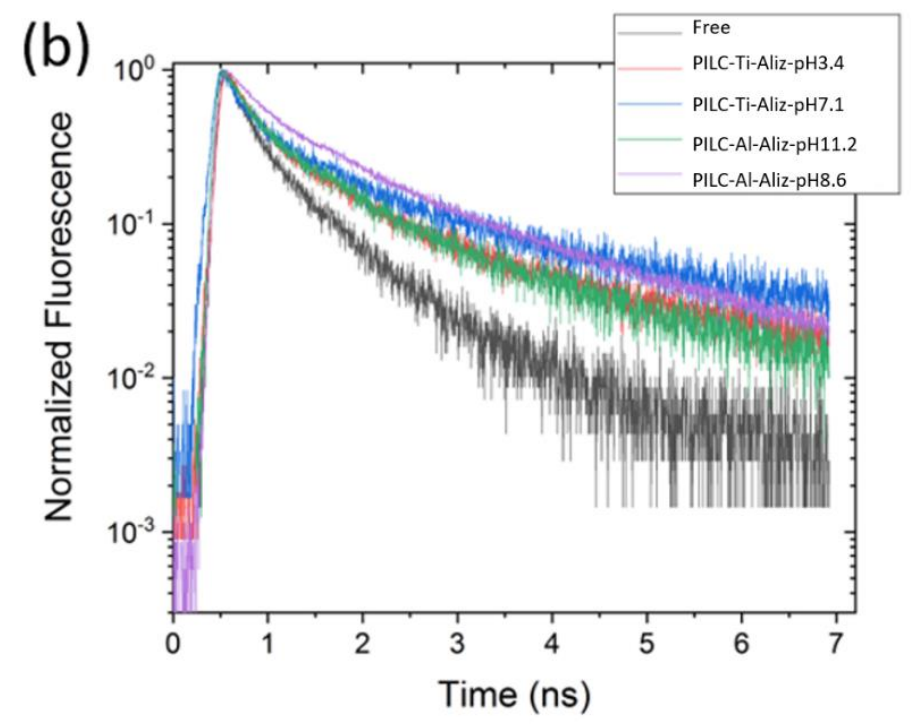

Figure 8: Fluorescence decays of carminic acid (a) and alizarin (b) free in solution and loaded on different pillared clays.

Table I: Fluorescent lifetime $\left(\tau_{\mathrm{i}}\right)$ and average lifetime $\left(\tau_{\mathrm{AV}}\right)$ results for carminic acid free in solution and loaded on pillared clay for excitation wavelength $540 \mathrm{~nm}$ at emission wavelength $600 \mathrm{~nm}\left(\lambda_{\mathrm{e}}\right)$ Yield $=$ $100 \alpha_{i} \tau_{i} / \Sigma \alpha_{i} \tau_{i}$ represents the contribution of each emission to the total emission

\begin{tabular}{ccccccc}
\hline Samples & $\tau_{1}(\mathbf{n s}) /$ & $\tau_{2}(\mathbf{n s}) /$ & $\tau_{3}(\mathbf{n s}) /$ & $\tau_{4}(\mathbf{n s}) /$ & $\tau_{(\mathbf{a v})}(\mathbf{n s})$ & $\chi^{2}$ \\
& $($ yield $)$ & $($ yield $)$ & $($ yield $)$ & $($ yield $)$ & & \\
\hline CA-H ${ }_{2} \mathrm{O}$ & $0.496(15.9 \%)$ & $0.099(62.7 \%)$ & $0.048(21.4)$ & - & 0.151 & 0.87 \\
PILC-Ti-CA-pH5 & $2.202(25.6 \%)$ & $0.774(40 \%)$ & $0.270(24.6 \%)$ & $0.059(9.9 \%)$ & 0.945 & 1.08 \\
PILC-Ti-CA-pH2.5 & $1.723(9.6 \%)$ & $0.496(53.2 \%)$ & $0.147(22.2 \%)$ & $0.047(15 \%)$ & 0.469 & 1.00 \\
PILC-Al-CA-pH4.9 & $2.798(33.7 \%)$ & $0.981(41.8 \%)$ & $0.326(20.5 \%)$ & $0.053(4.1 \%)$ & 1.421 & 1.02 \\
PILC-Al-CA-pH7 & $2.91(37.3 \%)$ & $1.014(43.9 \%)$ & $0.322(16.1 \%)$ & $0.048(2.6 \%)$ & 1.584 & 0.99 \\
\hline
\end{tabular}

Table II: Fluorescent lifetime $\left(\tau_{\mathrm{i}}\right)$ and average lifetime $\left(\tau_{\mathrm{AV}}\right)$ results for alizarin free in solution and loaded on pillared clay for excitation wavelength $540 \mathrm{~nm}$ at emission wavelength $600 \mathrm{~nm}\left(\lambda_{\mathrm{e}}\right)$ Yield $=$ $100 \alpha_{i} \tau_{i} / \Sigma \alpha_{i} \tau_{i}$ represents the contribution of each emission to the total emission

\begin{tabular}{cccccc}
\hline \multirow{2}{*}{ Samples } & $\tau_{1}(\mathbf{n s}) /$ & $\tau_{2}(\mathbf{n s}) /$ & $\tau_{3}(\mathbf{n s}) /$ & $\tau_{(\text {av })}(\mathbf{n s})$ & $\chi^{2}$ \\
& $($ yield $)$ & $($ yield $)$ & $($ yield $)$ & & \\
\hline Aliz- $\mathrm{H}_{2} \mathrm{O}$ & $1.094(37.7 \%)$ & $0.359(49.1 \%)$ & $0.059(13.2 \%)$ & 0.596 & 0.84 \\
\hline
\end{tabular}




\begin{tabular}{llllll}
\hline PILC-Al-Aliz-pH11.2 & $2.315(45.3 \%)$ & $0.585(42.5 \%)$ & $0.125(12.2 \%)$ & 1.313 & 1.09 \\
PILC-Al-Aliz-pH8.4 & $2.78(48.5 \%)$ & $0.846(41.7 \%)$ & $0.189(9.8 \%)$ & 1.721 & 1.00 \\
PILC-Ti-Aliz-pH3.4 & $3.217(42.2 \%)$ & $0.713(39.5 \%)$ & $0.183(18.2 \%)$ & 1.674 & 1.26 \\
PILC-Ti-Aliz-pH7.1 & $3.372(54.5 \%)$ & $0.749(32.6 \%)$ & $0.183(12.9 \%)$ & 2.105 & 1.30 \\
\hline
\end{tabular}

385

4.7 Colours and hue of pigments

387

The colours and hue variation of the pillared samples upon CA and Aliz adsorption were $\mathrm{pH}$

388 dependent (Figure 9). It is known that carminic acid presents three different values of $\mathrm{pK}_{\mathrm{a}}$ 389 (2.8, 5.4 and 8.1) and alizarin has two different values (6.6-7.5 and 12.4-13.5). In solution, 390 Aliz occurs in the form of partially dissociated yellow molecules at $\mathrm{pH}$ below 5.2. At $\mathrm{pH}$ 6-10

391 it is deprotonated and occurs in red monovalent cations. Finally, it occurs in the violet di392 anionic form at $\mathrm{pH}$ about 12 [43]. In turn, $\mathrm{CA}$ is present, in acid $\mathrm{pH}$, in the orange 393 monoanionic form. Indeed, $\mathrm{CA}$ bears one negative charge at $\mathrm{pH}$ about 4 and is entirely 394 negative in neutral medium [1]. At $\mathrm{pH} \mathrm{8}$, it is completely deprotonated and is present, in 395 solution, in the violet colour tri-anionic molecule. From these observations, at low values of $396 \mathrm{pH}$ the interactions between organic dyes and clay surface is globally driven by electrostatic 397 forces. Whereas at higher values of $\mathrm{pH}$ the interactions can occur through complexation of the 398 catechol and hydroxy-keto groups of chromophore structures with the metallic cations of the 399 pillars present in the interlamellar spaces of montmorillonite. Furthermore, it is also known 400 that intensity of colours is dependent of the amount of the adsorbed organic dye. 


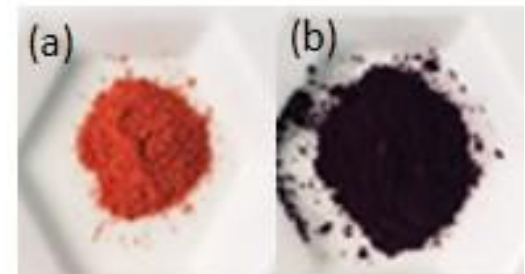

(c)

(d)
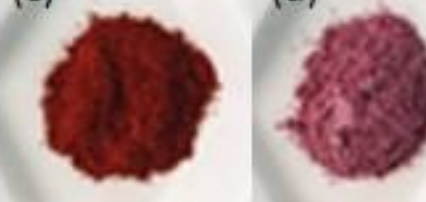

402

403

404

405

406

407

408

409

410

411

412

1) PILC-Al-Aliz-pH11.2

2) PILC-Al-Aliz-pH8.4

3) PILC-Al-CA-pH4.9

4) PILC-Al-CA-pH2.5

5) PILC-Ti-CA-pH2.5

6) PILC-Ti-CA-pH8.0

7) PILC-Ti-Aliz-pH8.4

8) PILC-Ti-Aliz-pH11.7

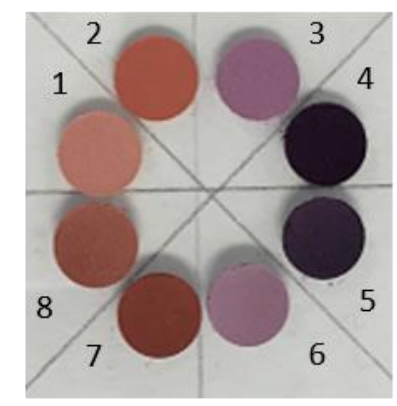

$340 \mathrm{~h}$

irradiation
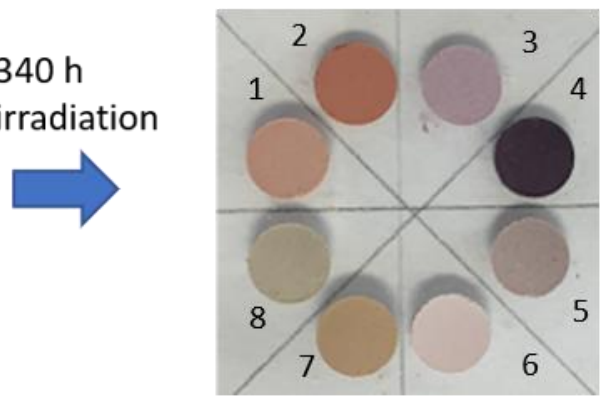

413 Figure 10(a). Solid pigments samples before and after LED irradiation based Aliz and CA dyes 

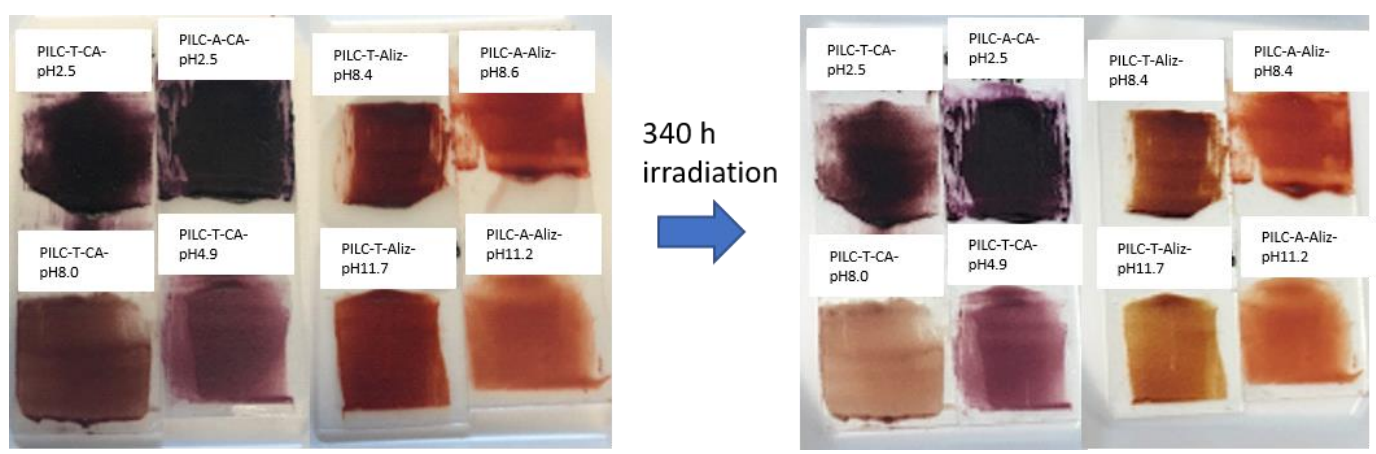

417 Figure 10(b). Oil paint formulations unexposed and exposed LED irradiation. Hybrid pigments based 418 Aliz and CA organic dyes onto pillared clays.

The spectral reflectance distribution curve of hybrid pigments, before and after photoaging

421 test, are shown in Figure 11 and 12. In general, all samples present similar spectra. The 422 differences are observed for PILC-Ti-CA-pH2.5 and PILC-Ti-Aliz-pH8.4 solid pigment

423 where after light exposure, a shift at higher values of reflectance is observed. It is probably

424 due to the degradation/fading of the dye as observed in Figure 11. Oil painting samples had 425 lower reflectance values compared to the solid pigments and all samples present very similar 426 reflectance spectrum, according to Figure 12, suggesting less variation of colors consequently 427 high resistance of the formulations even after a long time of irradiation. 

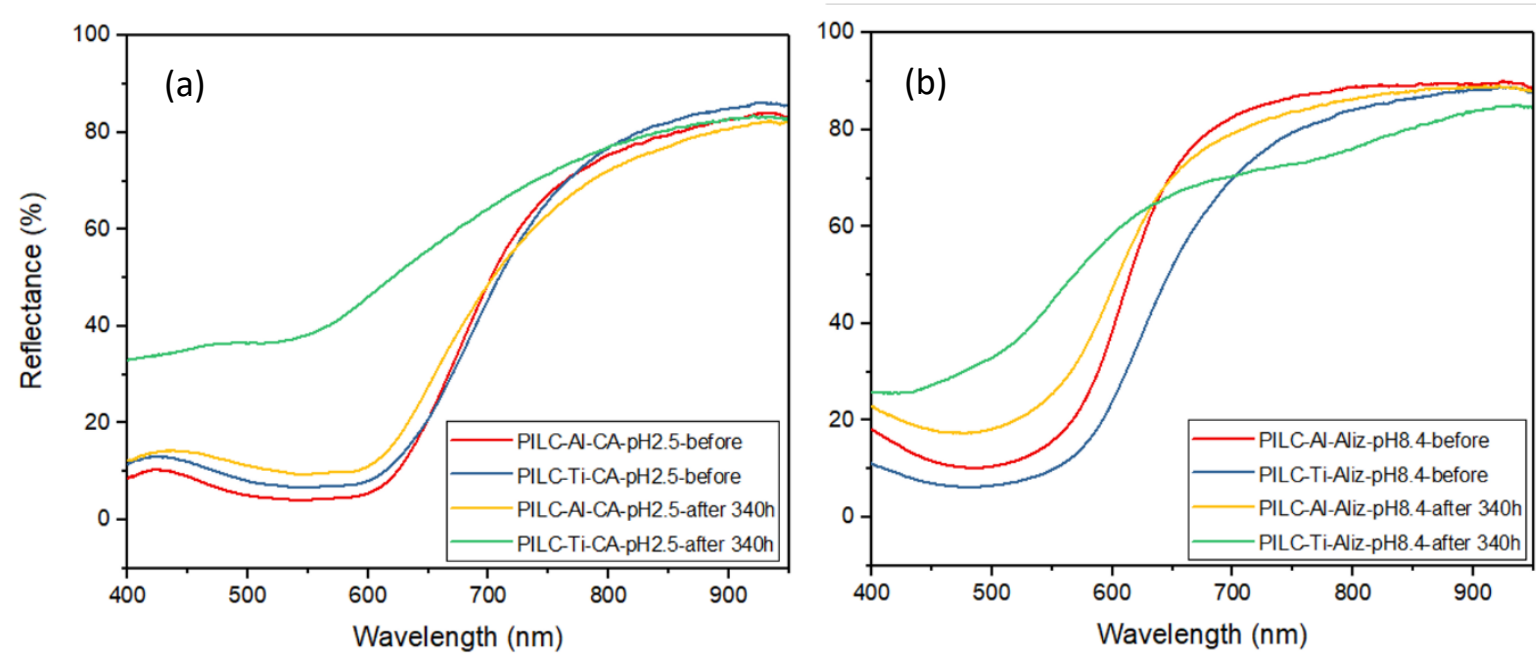

430

431

432

433

434

435

436

437

438

439

440

441

442

443

Figure 11. Reflectance spectrum of solid pigments before and after light exposure for $340 \mathrm{~h}$ for (a) carminic acid and (b) alizarin dyed samples.
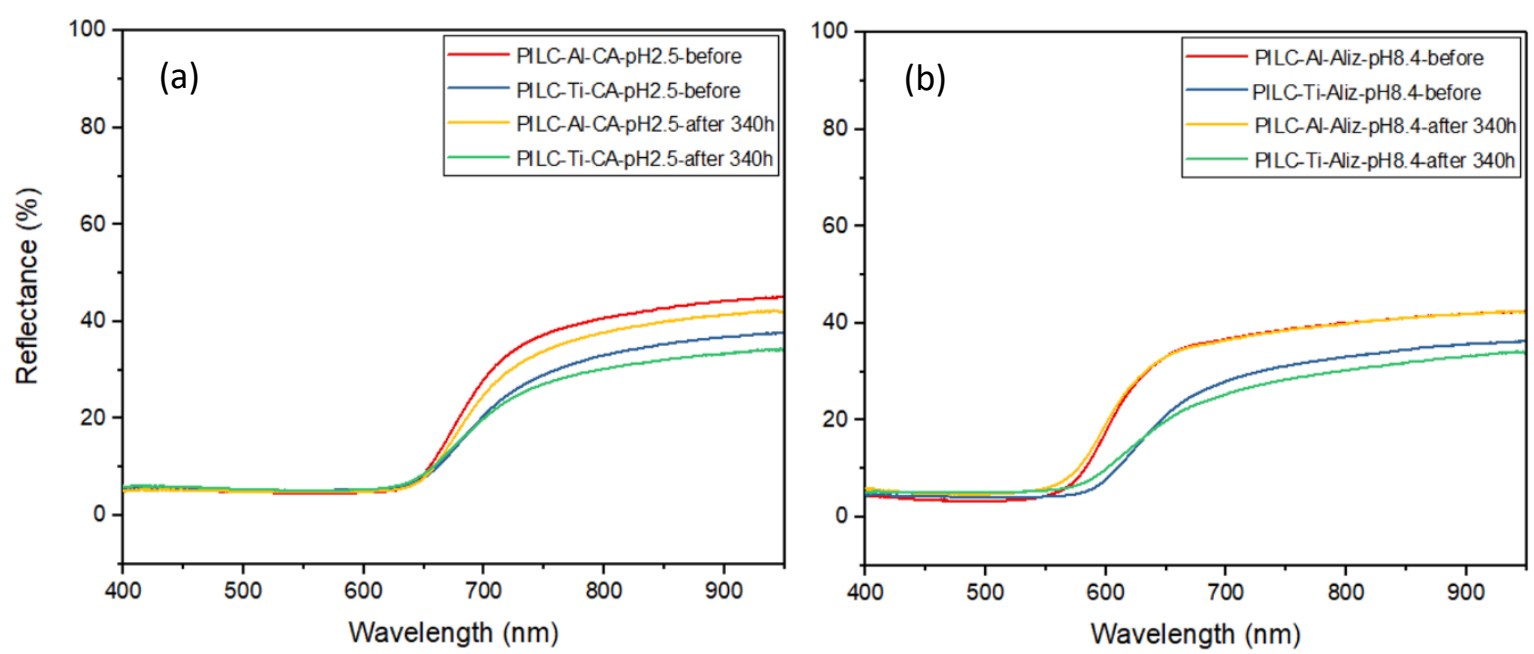

Figure 12. Reflectance spectra of oil paintings formulation before and after light exposure for $340 \mathrm{~h}$ for (a) CA and (b) Aliz dyed samples.

The measurement over CIE $L^{*}, a^{*}$ and $b^{*}$ scales notices a quantitative change over the pigments. $\Delta E^{*}$ variation values are due to the change of pigment structure after light exposure. Higher values of $\Delta E^{*}$ are observed for solid pigments (Figure 13a). Indeed, $\Delta \mathrm{E}^{*}<14$ for dyes adsorbed on PILC-Al samples and $\Delta \mathrm{E}^{*}<36$ for dyes adsorbed in PILC-Ti clays are noticed. Al-pillared based pigments have been shown more stable than Ti-pillared based. This may probably due to the photocatalytic property of the anatase phase that remains even after the 
complexation of the pillared material with the dye molecule. In all samples, lower values of $445 \Delta E^{*}$ are observed for oil paint formulations, mainly aluminium based samples (Figure 13b).

446 These results suggested high stability of the ink formulations upon incorporation of drying oil,

447 probably the linseed oil in the surface of the pigment, disturbs the reactions with oxygen.

448 When irradiation is performed in air, the clay will have much faster access to new oxygen

449 coming from outside which would result in higher dye photobleaching rates at that region [45]

450 because the oxygen seems to play a key role for the dye photostability. Linseed oil can be

451 acting as an inhibitor in the formation of the radicals, forming a photoresist protective layer.

452

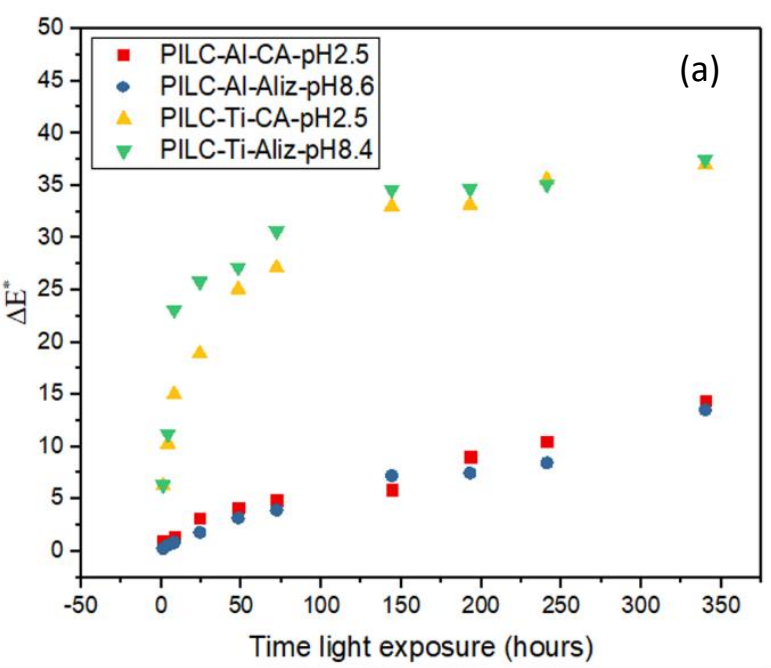

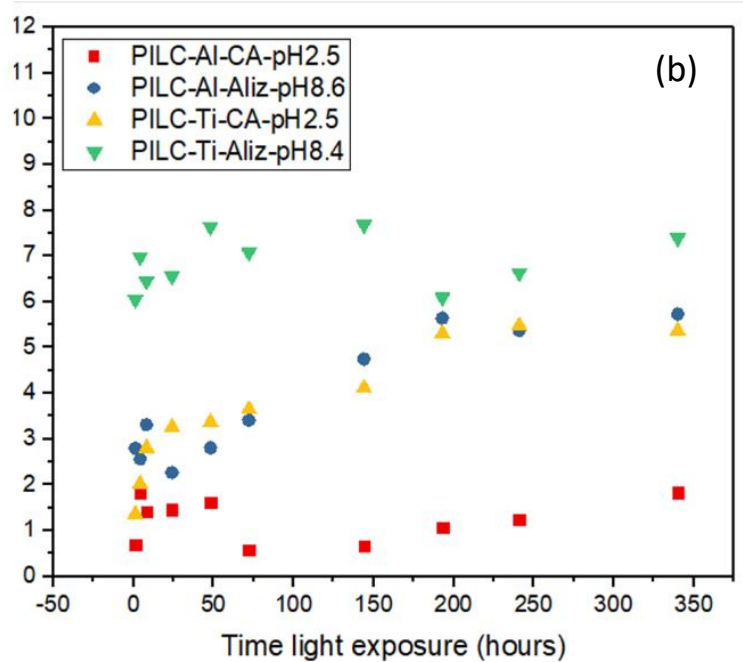

453

454

455

Figure 13. Colour difference $\left(\Delta \mathrm{E}^{*}\right)$ between (a) solid pigments and (b) oil painting formulation samples exposed to the light-induced aging for $340 \mathrm{~h}$.

According to these results, after light exposure, fading occurs in the solid pigments, especially in samples pillarized with titanium cations. Aluminum-based samples are more stable due to the strong interactions between the dye molecules and the modified clay, that retard photodegradation. The painting formulations exhibit minor variations in the $L^{*}, a^{*}$ and $b^{*}$ parameters after a long period of exposure to light, perhaps the formulations inhibit the hydroperoxides formation that accelerate the photo-oxidation process [46]. 


\subsection{CONCLUSIONS}

464

Hybrid pigments were prepared by stabilization of organic dyes onto pillared

\section{6}

467

468

469

470

471

472

473

474

475 montmorillonite. XDR, TEM and BET analyses suggest that pillaring process occurs. The interactions between chromophore groups and clay surface is driven by electrostatic forces and/or complexation between metallic cations in the interlamellar space and ketone and hydroxyl functions in the dye molecule. These results were highlighted by Infrared and NMR experiments. Fluorescence analysis report that increase of average lifetime for dyes upon adsorption on modified clay confirm interactions between organic dyes and clay mineral and underline the strong dependence on the speciation. Different parameters influence the color and hue of the hybrids the $\mathrm{pH}$, the amount of the adsorbed dyes and the nature of metallic cations in the interlayer space. Oil paint formulations simulate real materials used in paintings. High stability of the organic-inorganic hybrids, especially from aluminium pillared clays dyed with carminic acid and alizarin, indicate that these can be applied as new stable lake pigments.

\subsection{ACKNOWLEDGEMENTS}

We acknowledge the financial support from the CAPES/COFEBUB (Project $n^{\circ} 835 / 15$ ). The authors thank the Île-de-France region and CNRS for funding.

\subsection{REFERENCES}

[1] Fournier F, de Viguerie L, Balme S, Janot JM, Walter P, Jaber M. Physico-chemical 
characterization of lake pigments based on montmorillonite and carminic acid. Applied Clay Science 2015;130:12-7.

[2] Bechtold T and Mussak R. Handbook of Natural Colorants 2009, Wiley, United Kingdon.

[3] Tian G, Wang W, Wang D, Wang Q, Wang A. Novel environment friendly inorganic red pigments based on attapulgite. Powder Technology 2017;315:60-7.

[4] Cao L, Fei X, Zhao H. Dyes and Pigments Environmental substitution for PbCrO 4 pigment with inorganic-organic hybrid pigment. Dyes and Pigments 2017;142:100-7.

[5] Pereira F, Sousa K, Cavalcanti G, França D, Queiroga L, Santos I, Fonseca M, Jaber M. Green biosorbents based on chitosan-montmorillonite beads for anionic dye removal. Journal of Environmental Chemical Engineering 2017;5:3309-18.

[6] Thangaraj V, Bussiere J, Janot JM, Bechelany M, Jaber M, Subramanian S, et al. Fluorescence Quenching of Sulforhodamine Dye over Graphene Oxide and Boron Nitride Nanosheets. European of Journal Inorganic Chemistry 2016;2016:2125-30.

[7] Zhang A, Mu B, Luo Z, Wang A. Dyes and Pigments Bright blue halloysite / CoAl 2 O 4 hybrid pigments: Preparation, characterization and application in water-based painting. Dyes and Pigments 2017;139:473-81.

[8] Pérez E, Ibarra IA, Guzmán A, Lima E. Hybrid pigments resulting from several guest dyes onto $\gamma$-alumina host: A spectroscopic analysis. Spectrochimica Acta Part A Mol ecular and Biomolecular Spectroscopy 2017;172:174-81.

[9] Claro A, Melo MJ, Schäfer S, de Melo JSS, Pina F, van den Berg KJ, et al. The use of microspectrofluorimetry for the characterization of lake pigments. Talanta 
509 [10] Perez-Ramirez E, Lima E, Guzman A. Natural betalains supported on $\gamma$-alumina: A wide family of stable pigments. Dyes and Pigments 2015;120:161-8.

511

512

513

514

515

516

517

518

519

520

521

522

523

524

525

526

527

528

529

[11] Anselmi C, Capitani D, Tintaru A, Doherty B, Sgamellotti A, Miliani C. Beyond the color : A structural insight to eosin-based lakes. Dyes and Pigments 2017;140:297-311.

[12] Mintova S, Jaber M, Valtchev V. Nanosized microporous crystals: emerging applications. Chemical Society Reviews 2015;44:7207-33.

[13] El Adraa K, Georgelin T, Lambert JF, Jaber F, Tielens F, Jaber M. Cysteinemontmorillonite composites for heavy metal cation complexation: A combined experimental and theoretical study. Chemical Engineering Journal 2017;314:406-17.

[14] Arnold, D.E. Maya Blue and Palygorskite: A second possible pre-Columbian source. Ancient Mesoamerica 2005, 16, 51-62.

[15] Cocoletzi GH, Canto G. Trapping and diffusion of organic dyes inside of palygorskite clay: The ancient Maya Blue pigment. Microporous and Mesoporous Materials 2017;249.

[16] Wu S, Duan Z, Hao F, Xiong S, Xiong W, Lv Y, et al. Preparation of acid-activated sepiolite / Rhodamine B @ SiO 2 hybrid fl uorescent pigments with high stability. Dyes and Pigments 2017;137:395-402.

[17] Tian, G., Wang, W., Mu, B., Wang, Q., Wang, A., 2017a. Cost-efficient, vivid and stable red hybrid pigments derived from naturally available sepiolite and halloysite. Ceramics International 43, 1862-1869.

[18] Kittinaovarat S, Kansomwan P, Jiratumnukul N. Chitosan / modified montmorillonite 
beads and adsorption Reactive Red 120. Applied Clay Science 2010;48:87-91.

531 [19] Jaber, M., Georgelin, T., Bazzi, H., Costa-torro, F., Clodic, G., 2014. Selectivities in adsorption and peptidic condensation in the (arginine and glutamic acid)/montmorillonite clay system. Journal of Physical Chemistry C 118, 44, 25447-25455

[20] Gil A, Assis FCC, Albeniz S, Korili SA. Removal of dyes from wastewaters by adsorption on pillared clays. Chemical Engineering Journal 2011;168:1032-40.

536

537

538

539

540

541

[21] Gil A, Gandía LM, Vicente MA. Recent Advances in the Synthesis and Catalytic Applications of Pillared Clays. Catalysis Reviews, 2017;4940.

[22] Li K, Lei J, Yuan G, Weerachanchai P, Wang JY, Zhao J, et al. Fe-, Ti-, Zr- and Alpillared clays for efficient catalytic pyrolysis of mixed plastics. Chemical Engineering Journal 2017;317:800-9.

[23] Tangaraj V, Janot J, Jaber M, Bechelany M, Balme S. Adsorption and photophysical properties of fluorescent dyes over montmorillonite and saponite modified by surfactant. Chemosphere 2017, 184 1355-1361.

[24] Bergaoui L, Lambert J-F, Suquet H, Che M. CuII on Al13-Pillared Saponites: Macroscopic Adsorption Measurements and EPR Spectra. Journal of Physical Chemistry. 1995;99:2155-61.

[25] Tomul F, Turgut Basoglu F, Canbay H. Determination of adsorptive and catalytic properties of copper, silver and iron contain titanium-pillared bentonite for the removal bisphenol A from aqueous solution. Applied Surface Science 2016;360:579-93.

[26] MacHatova, Z., Barbierikova, Z., Poliak, P., Jancovicova, V., Lukes, V., Brezova, V., 2016. Study of natural anthraquinone colorants by EPR and UV/vis spectroscopy. Dyes 
and Pigments 132, 79-93

553

554

555

556

557

558

559

560

561

562

563

564

565

566

567

568

569

570

571

572

573

574

[27] Miliani, C., Romani, a, Favaro, G., 2000. Acidichromic effects in 1, 2-di-and 1, 2, 4trihydroxyanthraquinones. A spectrophotometric and fluorimetric study. Journal of Physical Organic Chemistry 141-150.

[28] Vágvölgyi V, Kovács J, Horváth E, Kristóf J, Makó É. Investigation of mechanochemically modified kaolinite surfaces by thermoanalytical and spectroscopic methods. Journal of Colloids and Interface Science 2008;317:523-9.

[29] Balme S, Guégan R, Janot J-M, Jaber M, Lepoitevin M, Dejardin P, et al. Structure, orientation and stability of lysozyme confined in layered materials. Soft Matter 2013;9:3188.

[30] Cornu, D., Lin, L., Daou, M.M., Jaber, M., Krafft, J.-M., Herledan, V., Laugel, G., Millot, Y., Lauron-Pernot, H., 2017. Influence of acid-base properties of Mg-based catalysts on transesterification: role of magnesium silicate hydrate formation. Catalisis Science Technology 7, 1701-1712.

[31] Ksontini N, Ã WN, Ghorbel A. Al - Fe pillared clays : Synthesis, characterization and catalytic wet air oxidation activity. Journal of Physics and Chemistry of Solids 2008;69:1112-5.

[32] Kumararaja P, Manjaiah KM, Datta SC, Sarkar B. Remediation of metal contaminated soil by aluminium pillared bentonite : Synthesis, characterisation, equilibrium study and plant growth experiment. Applied Clay Science 2017;137:115-22.

[33] Ooka C, Akita S, Ohashi Y, Horiuchi T, Suzuki K, Komai S, et al. Crystallization of hydrothermally treated $\mathrm{TiO} 2$ pillars in pillared montmorillonite for improvement of the photocatalytic activity. Journal of Materials Chemistry 1999:2943-52. 
[34] Barama S, Davidson A, Barama A, Boukhlouf H, Casale S, Calers C, et al. Dephosphatation under UV light of water by Ti-PILC with activation by secondary species (La, Se, and Rb). Comptes Rendus Chimie 2017;20:7-19.

[35] Liang X, Qi F, Liu P, Wei G, Su X, Ma L, et al. Performance of Ti-pillared montmorillonite supported Fe catalysts for toluene oxidation: The effect of $\mathrm{Fe}$ on catalytic activity. Applied Clay Science, 2016;132-133:96-104.

[36] Chmielarz L, Piwowarska Z, Kuśtrowski P, Wegrzyn A, Gil B, Kowalczyk A, et al. Comparison study of titania pillared interlayered clays and porous clay heterostructures modified with copper and iron as catalysts of the DeNOx process. Applied Clay Science, 2011;53:164-73.

[37] Bergaoui L, Lambert JF, Vicente-Rodriguez MA, Michot LJ, Villiéras F. Porosity of Synthetic Saponites with Variable Layer Charge Pillared by Al-13 Polycations. Langmuir, 1995;11:2840-52.

[38] Hutson ND, Hoekstra MJ, Yang RT. Control of microporosity of Al O -pillared clays : effect of $\mathrm{pH}$, calcination temperature and clay cation exchange capacity. Microporous and Mesoporous Materials, 80, 1999;28:447-59.

[39] Roca Jalil ME, Baschini M, Rodríguez-Castellón E, Infantes-Molina A, Sapag K. Effect of the Al/clay ratio on the thiabendazol removal by aluminum pillared clays. Applied Clay Science 2014;87:245-53.

[40] Giustetto R, Wahyudi O, Corazzari I, Turci F. Applied Clay Science Chemical stability and dehydration behavior of a sepiolite / indigo Maya Blue pigment. Applied Clay Science, 2011;52:41-50.

[41] Doskocz M, Kubas K, Frackowiak A, Gancarz R. NMR and ab initio studies of Mg2+, 
599 [42] Fain, V.Y., Zaitsev, B.E., Ryabov, M. a, 2004. Metal Complexes with 1, 5- and 600 Electronic Absorption Spectra and Structure of Ligands, Russian Journal of Coordination

602

603

604

605

606

607

608

609

610

611

612

613

614 Chemistry 30, 385-389.

[43] Epstein M, Yariv S. Visible-spectroscopy study of the adsorption of alizarinate by Almontmorillonite in aqueous suspensions and in solid state. Journal of Colloids Interface Science, 2003;263:377-85.

[44] Feng W, Nansheng D, Helin H. Degradation mechanism of azo dye C. I. reactive red 2 by iron powder reduction and photooxidation in aqueous solutions. Chemosphere 2000;41:1233-8.

[45] Lencione D, Gehlen MH, Trujillo LN, Leitao RCF, Albuquerque RQ. The spatial distribution of the photostability of thionine in zeolite $\mathrm{L}$ nanochannels investigated by Photobleaching Lifetime Imaging Microscopy. Photochemical and Photobiology Science, 2016;15:398-404.

[46] Wu T, Liu G, Zhao J, Hidaka H, Serpone N. Evidence for H2O2 Generation during the TiO2-Assisted Photodegradation of Dyes in Aqueous Dispersions under Visible Light Illumination. Journal of Physical Chemistry B 1999;103:4862-7. 